\title{
A LYAPUNOV-TYPE INEQUALITY FOR A FRACTIONAL DIFFERENTIAL EQUATION WITH HADAMARD DERIVATIVE
}

\author{
QinghuA MA, ChaO MA AND JinXUN WANG
}

Abstract. In this work, a Lyapunov-type inequality is obtained for the case when working with a fractional boundary value problem with the Hadamard derivative.

Mathematics subject classification (2010): Please write....

Keywords and phrases: Lyapunov inequality, Hadamard fractional derivative, boundary value problem, Green's function.

\section{REFERENCES}

[1] A. A. Kilbas, H. M. SRivastava And J. J. Trujillo, Theory and Applications of Fractional Differential Equations, North-Holland Mathematics Studies, Vol. 204, Elsevier, Amsterdam, 2006.

[2] K. S. Miller AND B. Ross, An Introduction the the Fractional Calclus and Fractional Equations, Wiley, New York, 1993.

[3] I. Podlubny, Fractional Differential Equations, Academic Press, New York, 1993.

[4] R. C. BRown, D. B. Hinton, Lyapunov inequalities and their applications, In: Survey on Classical Inequalities (Ed. T. M. Rassias), Math. Appl. 517, Kluwer Acad. Publ., Dordrecht-London (2000), $1-25$.

[5] A. TIRYAKI, Recent developments of Lyapunov-type inequalities, Adv. Dyn. Syst. Appl. 5 (2) (2010), 231-248.

[6] A. M. Lyapunov, Probleme général de la stabilité du mouvement, (French Transl. of a Russian paper dated 1893). Ann. Fac. Sci. Univ. Toulouse 2 (1907), 27-247; Reprinted in: Ann. Math. Studies, no. 17, Princeton (1947).

[7] R. A. C. FERREIRA, A Lyapunov type inequality for a fractional boundary value problem, Fract. Calc. Appl. Anal. 16 (2013), no. 4, 978-984.

[8] R. A. C. FERreira, On a Lyapunov-type inequality and the zeros of a certain Mittag-Leffler function, J. Math. Anal. Appl. 412 (2014), 1058-1063.

[9] M. JLELI, B. SAMET, Lyapunov type inequalities for a fractional differential equations with mixed boundary value problems, Math. Inequal. Appl., 18 (2) (2015), 443-451.

[10] J. RonG, C. Z. BAI, Lyapunov-type inequality for a fractional differential equations with fractional boundary value problems, Adv. Difference. Equ., (2015), 2015:82, 10 pp.

[11] J. R. WANG, Y. ZHOU AND M. MEDVEĎ, Existence and stability of fractional differential equations with Hadamard derivative, Topol. Methods in Nonlinear Anal., 41 (2013), 113-133.

[12] Q. H. MA, J. W. WANG, R. N. WANG AND X. H. KE, Study on some qualitative properties for solutions of a certain two-dimensional fractional differential system with Hadamard derivative, Appl. Math. Letters, 36 (2014), 7-13.

[13] B. AhmAD, S. K. NTOUYAs, On Hadamard fractional integro-differential boundary value problems, J. Appl. Math. Comput., 47 (2015), 119-131.

[14] J. R. WANG, Y. R. ZHANG, On the concept and existence of solutions for fractional impulsive systems with Hadamard derivatives, Appl. Math. Letters, 39 (2015), 85-90.

[15] Q. H. MA, R. N. WANG, J. W. WANG AND Y. C. MA, Qualitative analysis for solutions of a certain more generalized two-dimensional fractional differential system with Hadamard derivative, Appl. Math. Comput., 257 (2015), 436-445. 
[16] Ricardo Almeida, Delfim F. M. Torres, Computing Hadamard type operators of variable fractional order, Appl. Math. Comput., 257 (2015), 74-88. 